\title{
Child Disability and Caregiving in Low and Middle Income Countries: Big Data Approach on open data
}

Andrea Bizzego ${ }^{1} \quad$ Mengyu Lim ${ }^{2} \quad$ Greta Schiavon $^{1}$ Peipei Setoh $^{2} \quad$ Giulio Gabrieli ${ }^{2}$ Dagmara Dimitriou ${ }^{3}$ Gianluca Esposito $1,2,4, *$

${ }^{1}$ Department of Psychology and Cognitive Science, University of Trento, Italy

${ }^{2}$ School of Social Sciences, Nanyang Technological University, Singapore

${ }^{3}$ UCL Institute of Education, University College London, London, United Kingdom

${ }^{4}$ Lee Kong Chian School of Medicine, Nanyang Technological University, Singapore *gianluca.esposito@ntu.edu.sg; gianluca.esposito@unitn.it

Accepted for publication on: Research in Developmental Disabilities DOI will be available soon.

\begin{abstract}
Background: The presence of child disabilities might affect the amount of caregiving attention the child receives, with potential ramifications on the development of the child and increasing the likelihood of developing a more severe condition. Little is known about the association between child disabilities and caregiving practices in less developed countries, penalized by both lack of data and a research bias toward western societies.
\end{abstract}


Method: In this study, we apply data mining methods on a large ( $\mathrm{N}=29,525)$ dataset from UNICEF to investigate the association between caregiving practices and developmental disabilities of the children, and highlight the differences between intellectual and other disabilities.

Results: Our results highlight that, compared to other types of disabilities, intellectual disabilities increased the risk of being neglected by the caregiver in those activities oriented to the cognitive development. The education of the caregiver and the socioeconomical development of the country are actively involved in the moderation of the risk.

Conclusion: We demonstrated that educational policies of parental training, such as psychoeducation regarding intellectual disabilities and destigmatization campaigns, are needed to benefit parental practices in low- and middle-income countries.

developmental disabilities: parental involvement: low middle income countries; caregiving; child discipline; child education

What this paper adds: The paper makes use of a data-driven approach to uncover patterns of caregiving practices in an often overlooked population of children with disabilities in low- and middleincome countries. Using current theories of caregiving, child care and child neglect, the paper integrates these findings with already established frameworks of parental caregiving. 


\section{Introduction}

Parenting, although a commonly shared experience among most childbearing adults in different countries around the world, might be a stressful and demanding process for some parents (Brooks, 1981) as it requires time, effort and material resources such as childcare equipment, toys and child-friendly furniture, and paying for the child's daily living expenses, education and healthcare. These requirements have been broadly encapsulated as parental nurturance, or caregiving. Parental caregiving quality has important implications for child outcomes. For example, it was found that higher quality parental caregiving is correlated with more secure attachment (Rosen and Rothbaum, 1993) and decreased externalising behaviour (Rothbaum and Weisz, 1994) among young children, thereby contributing to the child's ability to regulate emotions. As proposed by (Bornstein and Putnick, 2012) and (Eisenberg et al., 2006), parental caregiving can be considered from two domains: cognitive and socioemotional. Cognitive caregiving refers to the methods parents use to guide their child's learning of the physical world, while socioemotional caregiving consists of the formation and development of interpersonal connection between the child and significant other human individuals. The two domains have significant influence over the child's ability to communicate, and to develop skills in socioemotional and mental processes (Bornstein, 1985; De Wolff and Van Ijzendoorn, 1997). Examples of cognitive caregiving practices include providing education to the child (Papousek and Bornstein, 1992), joint book reading (DeTemple et al., 2003) and storytelling (Egan, 2001), as well as child-directed speech (Thiessen et al., 2005). These specific examples of cognitive caregiving contribute to overall child development by accelerating the development of cognitive functioning (Behrman et al., 2004) and language ability (Bornstein et al., 1992). On the other hand, socioemotional caregiving may include practices such as interpersonal play (Tamis-Lemonda et al., 2002) and joint activities (Standley and Whipple, 2003). These practices have implications on the child's future ability to form social relationships with others beyond the immediate familial circles (Emde and Feinman, 1992).

The complexity of factors influencing parenting behaviour was explored in (Belsky, 1984)'s process model of parenting, where it was posited that determinants of parenting behaviour can be narrowed down into parental psychological resources, child characteristics and contextual sources of stress and support that mutually influence each other. In the present work, parental 
caregiving behaviour in terms of cognitive and socioemotional caregiving outlined above may be influenced due to the presence of several factors, such as the presence of intellectual or other disabilities in the child. This would fall under the category of child characteristics in the expanded version of (Belsky, 1984)'s model proposed by (Taraban and Shaw, 2018). Child developmental disabilities are conditions that arise from delays or impairments in the child's physical, learning, language or behavioral development (for Disease Control and Prevention, 2019). Significantly, these conditions affect 52.9 million children aged 5 and below in 195 different countries globally (Olusanya et al., 2018). Child disabilities can be classified into different categories depending on the nature and symptoms of the condition, such as physical disability (for example, spina bifida), sensory impairment (for example, blindness or deafness), and intellectual disability. In particular, intellectual disability (ID) is defined by the American Association on Intellectual and Developmental Disabilities as "limitations in both intellectual functioning and adaptive behaviour" which results in decreased overall intelligence (Schalock et al., 2010), with consequences in daily functioning and adaptive behavior (Tassé and Grover, 2013). Regardless of type of disability, parents of children with a disability generally experience greater parenting stress (Tomanik et al., 2004; Hassall et al., 2005) and poorer mental health (Oelofsen and Richardson, 2006), along with a host of other negative outcomes (Pelchat et al., 2003). The increased psychological stress experienced by these parents in turn contribute to lower quality caregiving and poorer child outcomes, such as poorer social competence (Anthony et al., 2005). (Hastings, 2002), using a family processes model, found that the increased parental stress, parental caregiving and the child's behavioural problems due to disability interact with each other, potentially contributing to a vicious cycle where both parental and child negative outcomes are exacerbated. For a vulnerable population as that of children suffering from ID or other disabilities (OD) (Engle et al., 2007), this knowledge is particularly significant for health professionals and family members as it can directly influence the child's prognosis.

When examining child disability in terms of specific diagnoses, differential diagnoses have varying impact on the child's lived experience and the behaviour and care provided by their surrounding sources of support. For example, (Eddy and Engel, 2008) reports a moderate effect of diagnosis type on five aspects of family outcomes, including the intensity of worry about the child and the degree of limitation and interruption of family activity. (Wei 
and Jennifer, 2012) similarly found that the type of disability affected family interaction differently, with conditions that caused emotional disturbances within the child to more strongly affect the frequency of negative family experiences. The above interaction between parental stress, caregiving and child behaviour was also seen in cases of child Autism Spectrum Disorder (Osborne and Reed, 2009), a condition that is co-morbid with up to $30 \%$ of child ID cases (Baio, 2014). Additionally, different from other common child disabilities, ID is typically construed as a condition that is inherently internal (Rapley, 2004) rather than external (as in the case of physical disabilities), and is similarly more stigmatized (Ruddick and Oliver, 2005) and poorly understood (Scior, 2011). For these reasons, the present paper will focus on the comparison between ID and OD within the context of parental caregiving.

From a meta-analysis conducted by (Maulik et al., 2011), the prevalence of ID is almost twice as high in low- and middle-income countries (LMIC) as compared to high-income countries, and is part of the larger trend of greater prevalence of child disability in general in LMIC (Department of Health and Social Care, 2001). Despite the unequal rates of prevalence of ID distributed globally, much of the research surrounding ID is conducted within cultural contexts that are more aligned with high-income countries (Henrich et al., 2010), resulting in disproportionate representation from LMIC in ID research. As a result, growing scientific focus is placed on conducting objective crosscultural research in the field of child development (Bornstein, 2014), in order to better serve the higher numbers of children with ID in LMIC worldwide (Pan, 2007). The lack of representation from LMIC is especially significant because of the presence of known differences between these countries and high-income regions, especially differences related to parenting beliefs and caregiving approaches. For example, attitudes regarding child disability is different in LMIC (Gaad, 2004; Fatimilehin and Nadirshaw, 1994; Wong et al., 2004). Parental struggles and priorities in LMIC are also varied, as parents who reside in lower income countries tend to experience higher levels of stress, which indirectly lowers caregiving quality and produces worse child outcomes (Noel et al., 2008). These differences undoubtedly limit the generalizability of existing studies exploring the relationships between ID, caregiving and parental characteristics. In order to obtain findings that are more ecologically valid and generalizable across the LMIC population, the present study therefore focuses on data obtained from parents and their children located in LMIC. 
A previous analysis on 13 LMIC (Bizzego et al., 2020) investigated the effect of the severity of child disability on different parenting practices, evidencing that children with more severe developmental disabilities are less cared and more physically punished. However, as the previous analysis only focused on severity of child disability in general, the difference between ID and OD were not considered. The differences between ID and OD in terms of caregiving will now be examined in this work.

\subsection{Aim of this Study}

This paper aims to investigate whether ID is associated with specific caregiving behaviours of parents and other caregivers, in particular concerning cognitive and socioemotional activities.

In particular, the study aims to answer the following questions:

1. Are children with ID more neglected by their parents than children with other disabilities?

2. Do mothers and fathers behave differently if their child has ID or OD, compared to if their child was typically developing (TD)?

In examining these questions, we also consider the differences between mothers and fathers, the effect of the education of the main caregiver, gender of the child and, more generally, of the socioeconomic development of each country.

Due to the scarcity in relevant current literature on the association between child ID and caregiving in LMIC, our study is exploratory in nature.

Using a large cross-country data set of children in LMIC $(\mathrm{N}=29,525)$ and adopting a data-driven approach, we aim to find patterns and provide directions for future research.

\section{Methods}

\section{$2.1 \quad$ Dataset}

Data from the 2005-2007 Multiple Indicator Cluster Survey (MICS) (United Nations Children's Fund, 2006) was used in this study. Data are public and can be retrieved online from mics.unicef.org. Developed and supported 
by UNICEF, MICS is an internationally-conducted household survey that reports data from more than 200 key physical and social indicators impacting the well-being of children, women and men worldwide. The MICS dataset was selected as it is the largest dataset available that involves multiple LMIC countries and investigates multiple aspects of parenting and child development.

MICS consists of separate questionnaires that address macro areas (such as Child development, Quality of the Housing Environment). Each macro area includes a number of modules that examine specific aspects; for example, there would be modules regarding Discipline in the Household macro area and modules regarding Caregiving in "Children under 5" macro area. Each module is targeted at certain members of the household within a given age range. In the present study, some subsets of MICS indicators (described below) were selected from relevant modules in order to extract information about child ID, OD and caregiving practices.

Target households for participation in MICS are selected randomly using a hierarchical process, beginning from census enumeration areas down to segments in each area, and finally narrowing down on the particular households within each segment (Bornstein et al., 2016).

\subsection{Participants}

The Child Disabilities module targets children aged between 2 and 9 years old and also consists of relevant indicators regarding parenting involvement for parents of children aged below 5 . Therefore, the final dataset that is used in the present study resulted from merging the Child Disability module and parenting indicators for children aged between 2 and 5 years. As a single household might host multiple families, we randomly sampled one child for each household and the child's parents.

The unit of this analysis was the child and the caregiving practices the child receives. However, since the role of the child's parents and of the living environment were also considered, each child unit is deeply related to the family and household. The final dataset thus comprises of data from 29,525 children (Boys $=14,973$ ) from 14 different LMICs (Table ).

Informed consent was sought at each site where data were collected. The current study protocol is approved by the Internal Review Board of the Nanyang Technological University (IRB-2020-04-040). 
Table 1: Partitioning of the sample of the study into the 14 Low and Middle Income Countries, with number of children in each disability group and the Human Development Index (HDI) of each country.

\begin{tabular}{lccccc} 
& $\mathrm{N}$ & $N_{T D}$ & $N_{I D}$ & $N_{O D}$ & $\mathrm{HDI}$ \\
\hline Albania & 668 & 547 & 43 & 78 & 0.709 \\
Belize & 394 & 225 & 49 & 120 & 0.676 \\
Cameroon & 2816 & 1733 & 301 & 782 & 0.470 \\
Central African Republic & 4093 & 1996 & 546 & 1551 & 0.328 \\
Djibouti & 322 & 156 & 74 & 92 & 0.414 \\
Georgia & 1093 & 759 & 96 & 238 & 0.712 \\
Ghana & 1722 & 1318 & 131 & 273 & 0.518 \\
Lao People's Democratic Republic & 2085 & 1805 & 116 & 164 & 0.511 \\
Mauritania & 3939 & 2531 & 377 & 1031 & 0.479 \\
Mongolia & 1883 & 1380 & 133 & 370 & 0.660 \\
Mozambique & 5230 & 4269 & 187 & 774 & 0.361 \\
Suriname & 1174 & 716 & 126 & 332 & 0.682 \\
Uzbekistan & 2457 & 2366 & 24 & 67 & 0.635 \\
Yemen & 1649 & 1085 & 212 & 352 & 0.478 \\
\hline
\end{tabular}




\subsection{Disability and Caregiving categories}

\subsubsection{Child Intellectual Disability}

To identify children with potential ID, the Child Disabilities module was used. The Child Disabilities module is based on "Ten Questions" (see Table 2) that screens, in a binary fashion (i.e. either "Yes/No"), for a range of impairments, but leaves the clinical diagnosis of the actual presence and severity of the disability to other appropriate clinical methods (Mung'alaOdera et al., 2004; Christianson et al., 2002). The Child Disabilities module is completed by either the mother or primary caregiver of the child.

Three questions are associated with cognitive/intellectual disability: a) When you ask the child to do something, does he/she understand what you say? b) Does the child learn to do thing like other?; c) Compared to other children, does the child appear mentally backward?;

Other questions correspond to other types of disabilities (such as language, sensory, or motor impairment) (Zaman et al., 1990; Hendricks et al., 2014; Bornstein and Hendricks, 2013) (see Table 2).

Based on the answers given by the main caregiver to the "Ten Questions", we categorized the children into three groups:

1. potential Intellectual Disability (ID): children with at least one reported intellectual disability $(\mathrm{N}=2,415)$;

2. potential Other Disabilities (OD): children with at least one reported disability, other than intellectual $(\mathrm{N}=6,224)$;

3. Typical Development (TD): all other children $(\mathrm{N}=20,886)$. This category of children have typical development.

As the Ten Questions is not a formal tool for clinical diagnosis of child disability, we are unable to definitively conclude if a child represented in the dataset indeed has a disability. Nonetheless, it has been reported that testing positive for a disability using the Ten Questions is significantly correlated to also being diagnosed with a disability during clinical evaluation (UNICEF et al., 2008), and is especially sensitive to severe disability (Durkin et al., 1994; Zaman et al., 1990). Additionally, (Durkin et al., 1995) revealed that the Ten Questions showed good internal and test-retest reliability. Originally designed to be used in resource-poor countries, the Ten Questions is also commonly used measure of child disability in developing countries (Maulik and Darmstadt, 2007), and is therefore ecologically valid. 
Table 2: "Ten Questions" that screen for child disabilities. The "Answer indicating disability" column indicates the answer associated with a potential disability condition. Question Answer indicating disability

\begin{tabular}{lll}
\hline Q1 & Any serious delay sitting, standing or walking? & Yes \\
Q2 & Does she/he have difficulty seeing in daytime or nighttime? & Yes \\
Q3 & Does she/he appear to have difficulty hearing? & Yes \\
Q4 & When you ask her/him to do something, does she/he seem to understand what you say? & No \\
Q5 & Does she/he have difficulty walking or moving? & Yes \\
Q6 & Does she/he have fits, become rigid or lose consciousness & Yes \\
Q7 & Does she/he learn to do thing like other? & No \\
Q8 & Can she/he says recognizable words? & No \\
Q9A & Can she/he name at least one object? (For 2 years old children) & No \\
Q9B & Is her/his speech in any way different from normal? (For children older than 2 years) & Yes \\
Q10 & Compared to other children does she/he appear mentally backward, dull or slow? & Yes \\
\hline
\end{tabular}

\subsubsection{Cognitive and Socioemotional Caregiving}

The Caregiving module from the "Questionnaire for Child under Five" of MICS investigates who in the household administers six main caregiving activities with the child. Three activities are related to the cognitive development of the child: "Read Books", "Tell Stories", "Spend Time/Name,Count,Draw", and three others correspond to socioemotional development: "Sing Songs", "Take Outside", "Play". For each activity, three questions ask whether the mother, the father, and other caregivers do the activity.

We categorized the children based on the number of caregiving activities performed. In particular, for each caregiver, we labeled a child as "neglected" if none of the caregiving activities are performed by the caregiver.

In addition to the caregiving and socioemotional activities, we also considered the total caregiving, including both the cognitive and socioemotional activities. A child is "neglected" in terms of total caregiving if no activity (cognitive or socioemotional) is performed.

In addition, we also labeled the children that are neglected by all caregivers.

\subsubsection{Moderators}

In investigating the associations between disability and caregiving, we took into account the possible influence of three moderators: the gender of the child (HL4 indicator, "Questionnaire for Children under Five"), the education of the main caregiver (whether or not the caregiver has ever attended school, ED2 indicator, "Household Questionnaire"), and the socioeconomic 
category of the country, quantified by the 2006 Human Development Index described above. From the HDI values, low HDI countries have a HDI value less than 0.5 , while high HDI countries have a HDI value equal or more than 0.5 .

\subsection{Analytical Plan}

The objective of the data analysis is to statistically assess whether the presence of disability is associated with increased risk of being neglected.

First we aimed at evaluating the incidence of the disabilities is different for each category of the moderators: for males and females, for caregiver with different education, and for each HDI group. These analyses were performed running a Pearson's chi-square test comparing the disability group and the categories of each moderator.

Then we investigated whether the three disability groups are associated with a different number of children that are neglected. These analyses were performed running a Pearson's chi-square test comparing the caregiving (neglected / not neglected) and the disability (TD, ID and OD) categories for each type of caregiving activities (Cognitive, Socioemotional, and Total).

For these first two steps of analysis we also report the standardized residuals of the contingency tables, to quantify the strength of the difference between observed and expected values.

Finally, we also investigated whether the association between disability and caregiving is moderated by the type of parent, child's gender, education of the main child's caregiver, and HDI of the country. To this aim, we separately ran the Pearson's chi-square test comparing the caregiving and the disability categories on each group of the moderating variables.

To quantify the difference between children with ID and with OD with respect to children with TD we reported the Odds Ratio (OR) of being neglected by the caregiver for each disability group $\left(O R_{I D}\right.$ and $\left.O R_{O D}\right)$. In addition, we also computed the OR of children with ID with respect to children with OD to quantify the difference between the two types of disability $\left(O R_{I D / O D}\right)$.

A multilevel logistic regression was finally performed to predict whether the child is neglected, considering the contribution of the type of disability (ID or OD), parent (Mother of Father), gender of child, education of the main child's caregiver, and Human Development index. 
Table 3: Standardized residuals of the contingency tables that compare the number of children in each disability group and the categories of the moderators considered in this study.

\begin{tabular}{lcccccc} 
& \multicolumn{2}{c}{ Gender } & \multicolumn{2}{c}{ Education of main caregiver } & \multicolumn{2}{c}{ HDI group } \\
& Males & Females & Never Attended School & Attended School & Low & High \\
\hline Typycal Development & -1.02 & 1.03 & -5.46 & 3.55 & -8.83 & 11.08 \\
Intellectual Disability & 1.04 & -1.05 & 6.08 & -3.95 & 5.74 & -7.20 \\
Other Disabilities & 1.22 & -1.24 & 6.22 & -4.04 & 12.60 & -15.80 \\
\hline
\end{tabular}

\section{Results}
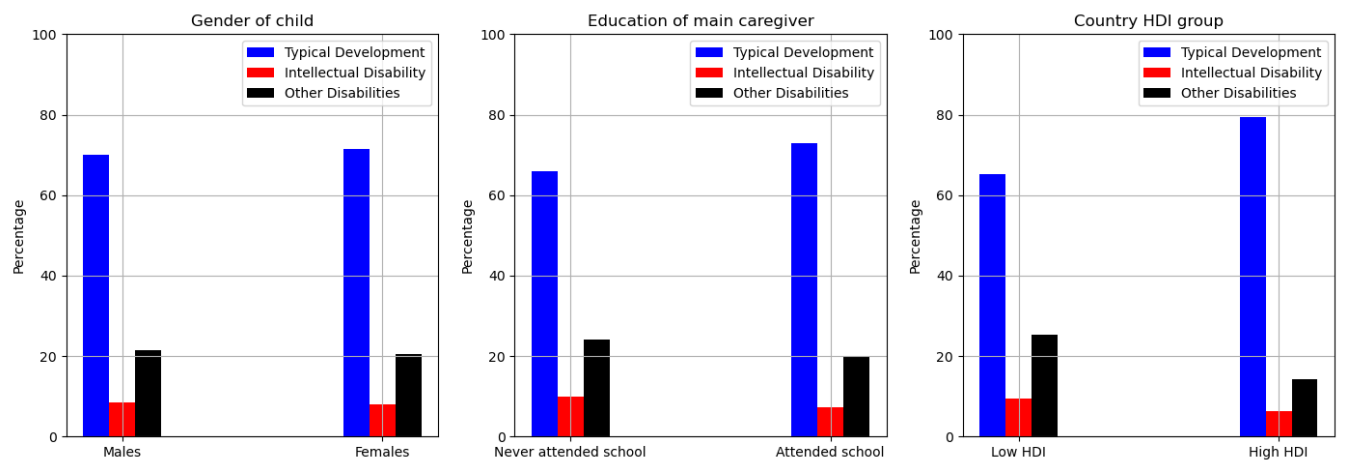

Figure 1: Incidence of child disabilities according by gender of the child (left), education of the main caregiver (middle), and country's HDI group (right).

The incidence of developmental disabilities (see Figure 1) is significantly associated with the child's gender $\left(\chi^{2}(2, \mathrm{~N}=29,525)=7.32, \mathrm{p}=0.026\right.$, Cramer's $\mathrm{V}=0.016)$, education of the main child's caregiver $\left(\chi^{2}(2, \mathrm{~N}=\right.$ $29,525)=150.03, \mathrm{p}<0.001$, Cramer's $\mathrm{V}=0.071)$, and the HDI group of the country $\left(\chi^{2}(2, \mathrm{~N}=29,525)=693.95, \mathrm{p}<0.001\right.$, Cramer's $\left.\mathrm{V}=0.153\right)$.

The standardized residuals (Table 3) evidence the strong effect of the education of the main caregiver and of the HDI on the incidence of intellectual and other disabilities.

The percentage of Boys with TD is lower (70.04\%) than Girls (71.46\%); conversely, the percentage of Boys with ID (8.42\%) and OD (21.54\%) is higher than Girls (ID: 7.93\%, OD: 20.61\%).

The percentage of children with TD is higher for children with educated caregiver $(72.81 \%)$ than non-educated caregiver $(65.83 \%)$; conversely, the 
percentage of children with ID and OD is higher for children with noneducated caregiver (ID: $10.04 \%$, OD: $24.13 \%$ ) than educated caregiver (ID: 7.40\%, OD: $19.79 \%$ ).

With respect to the HDI group of the country, in High HDI countries the percentage of children with TD is higher (79.43\%) than Low HDI countries (65.21\%); while the percentages of both children with ID and OD are higher in low HDI countries (ID: $9.40 \%$, OD: $25.39 \%$ ) than high HDI countries (ID: $6.26 \%$, OD: $14.31 \%)$.

\subsection{Caregiving and Developmental Disabilities}
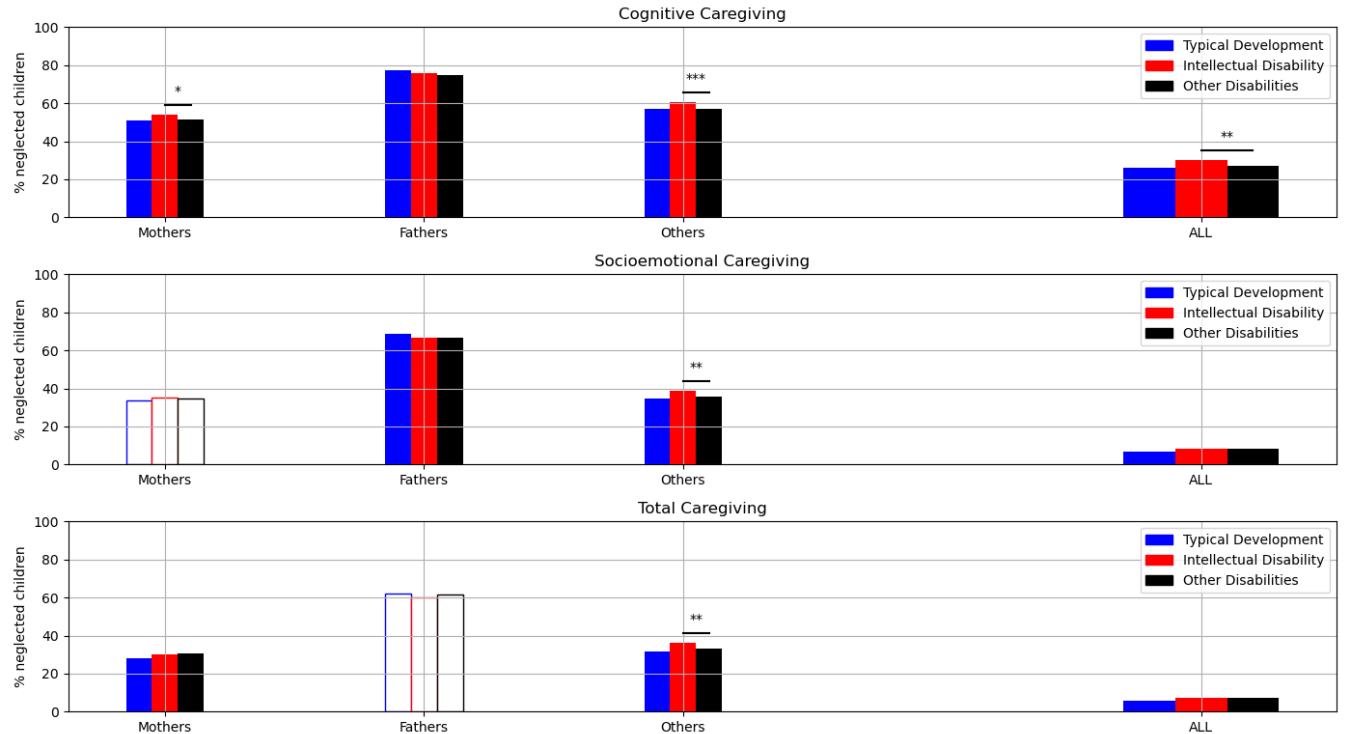

Figure 2: Percentages of neglected children for each category of caregiving activities and caregiver. White colored bars indicate non significant differences between the three groups.

Being neglected by all caregivers is significantly associated with the developmental status (TD, ID and OD), for both the cognitive $\left(\chi^{2}(2, \mathrm{~N}=\right.$ $29,525)=18.26, \mathrm{p}<0.001$, Cramer's $\mathrm{V}=0.025)$ and socioemotional $\left(\chi^{2}(2, \mathrm{~N}\right.$ $=29,525)=13.68, \mathrm{p}=0.001$, Cramer's $\mathrm{V}=0.022)$ caregiving activities and for the total caregiving $\left(\chi^{2}(2, \mathrm{~N}=29,525)=17.19, \mathrm{p}<0.001\right.$, Cramer's $\mathrm{V}=$ $0.024)$. 
Table 4: Odd Ratios of being neglected for children with ID $\left(O R_{I D}\right)$ and OD $\left(O R_{O D}\right)$ with respect to children with No Disabilities; and for children with ID with respect to children with $\mathrm{OD}\left(O R_{I D / O D}\right) . O R_{I D / O R^{\mathrm{S}}}$ in bold indicate that a significant association was found between the type of disability and the percentage of neglected children.

\begin{tabular}{|c|c|c|c|c|c|c|c|c|c|c|}
\hline \multirow[t]{2}{*}{. } & \multirow{2}{*}{$\mathrm{N}$} & \multicolumn{3}{|c|}{ Cognitive Caregiving } & \multicolumn{3}{|c|}{ Socioemotional Caregiving } & \multicolumn{3}{|c|}{ Total Caregiving } \\
\hline & & $O R_{I D}$ & $O R_{O D}$ & $O R_{I D / O D}$ & $O R_{I D}$ & $O R_{O D}$ & $O R_{I D / O D}$ & $O R_{I D}$ & $O R_{O D}$ & $O R_{I D / O D}$ \\
\hline AllCaregivers & 29525 & 1.22 & 1.04 & 1.17 & 1.21 & 1.18 & 1.02 & 1.25 & 1.23 & 1.02 \\
\hline Mother & 29525 & 1.14 & 1.03 & 1.11 & 1.06 & 1.05 & 1.01 & 1.12 & 1.13 & 1.00 \\
\hline Father & 29525 & 0.91 & 0.87 & 1.05 & 0.93 & 0.93 & 1.00 & 0.91 & 0.96 & 0.95 \\
\hline Others & 29525 & 1.17 & 1.00 & 1.18 & 1.20 & 1.06 & 1.14 & 1.22 & 1.06 & 1.14 \\
\hline Boys & 14973 & 1.24 & 1.06 & 1.16 & 1.14 & 1.11 & 1.03 & 1.15 & 1.09 & 1.06 \\
\hline Girls & 14552 & 1.20 & 1.02 & 1.18 & 1.30 & 1.27 & 1.02 & 1.37 & 1.39 & 0.98 \\
\hline Non educated & 8756 & 0.99 & 0.80 & 1.24 & 1.03 & 1.12 & 0.92 & 1.05 & 1.16 & 0.90 \\
\hline Educated & 20769 & 1.26 & 1.14 & 1.10 & 1.25 & 1.14 & 1.09 & 1.31 & 1.19 & 1.10 \\
\hline Low HDI & 18049 & 1.00 & 0.87 & 1.14 & 1.12 & 1.06 & 1.05 & 1.16 & 1.10 & 1.06 \\
\hline High HDI & 11476 & 1.44 & 1.03 & 1.41 & 1.06 & 1.04 & 1.01 & 1.00 & 1.01 & 0.99 \\
\hline
\end{tabular}

With respect to children with TD, all the OR are greater than one (see Table 4, first row, and Figure 2), indicating that children with disabilities are at increased risk of being neglected as compared to children with TD.

The percentage of neglected children is higher for cognitive caregiving activities than socioemotional for all groups. However, among children with disabilities, a significant difference between ID and OD was found only for cognitive caregiving activities $\left(\chi^{2}(1, \mathrm{~N}=8,639)=8.72, \mathrm{p}=0.003\right.$, Cramer's $\mathrm{V}=0.032)$, with increased risk of being neglected for ID compared to OD $\left(O R_{I D / O D}=1.17\right)$.

The standardized residuals (Table 5) evidence the effect of Intellectual Disability to increase the number of children that are neglected in the cognitive caregiving activities. Other disabilities, instead, are more associated to socioemotional and total caregiving activities.

\subsubsection{By parent}

We also investigate whether mothers and fathers show specific patterns of association between child disability and caregiving (Table 4, and Figure 2).

For mothers, there is a significant association between the type of disability and being neglected for the cognitive $\left(\chi^{2}(2, \mathrm{~N}=29,525)=9.52\right.$, $\mathrm{p}=0.009$, Cramer's $\mathrm{V}=0.018)$ and total activities $\left(\chi^{2}(2, \mathrm{~N}=29,525)=\right.$ 
Table 5: Standardized residuals of the contingency tables that compare the number of neglected children for each disability group

\begin{tabular}{lcccccc} 
& \multicolumn{2}{c}{ Cognitive } & \multicolumn{2}{c}{ Socioemotional } & \multicolumn{2}{c}{ Total } \\
Disability group & Not neglected & Neglected & Not neglected & Neglected & Not neglected & Neglected \\
\hline Typical Development & 0.84 & -1.40 & 0.54 & -1.92 & 0.56 & -2.17 \\
Intellectual Disability & -2.01 & 3.35 & -0.51 & 1.81 & -0.50 & 1.96 \\
Other Disabilities & -0.29 & 0.48 & -0.67 & 2.39 & -0.71 & 2.75 \\
\hline Intellectual Disability & -1.32 & 2.13 & -0.05 & 0.18 & -0.04 & 0.13 \\
Other Disabilities & 0.82 & -1.33 & 0.03 & -0.11 & 0.02 & -0.08 \\
\hline
\end{tabular}

18.16, $\mathrm{p}<0.001$, Cramer's $\mathrm{V}=0.025)$, but not for socioemotional activities.

A significant difference between ID and OD was found for cognitive caregiving activities only $\left(\chi^{2}(1, \mathrm{~N}=8,639)=4.84, p=0.028\right.$, Cramer's $\mathrm{V}=$ $0.024)$, with increased risk of being neglected by the mother for ID compared to $\mathrm{OD}\left(O R_{I D / O D}=1.11\right)$.

For fathers, this association is significant for cognitive $\left(\chi^{2}(2, \mathrm{~N}=29,525)\right.$ $=19.21, \mathrm{p}<0.001$, Cramer's $\mathrm{V}=0.026)$ and socioemotional caregiving activities $\left(\chi^{2}(2, \mathrm{~N}=29,525)=7.42, \mathrm{p}=0.024\right.$, Cramer's $\left.\mathrm{V}=0.016\right)$, but not for total activities. No significant difference is found between children with ID and children with OD.
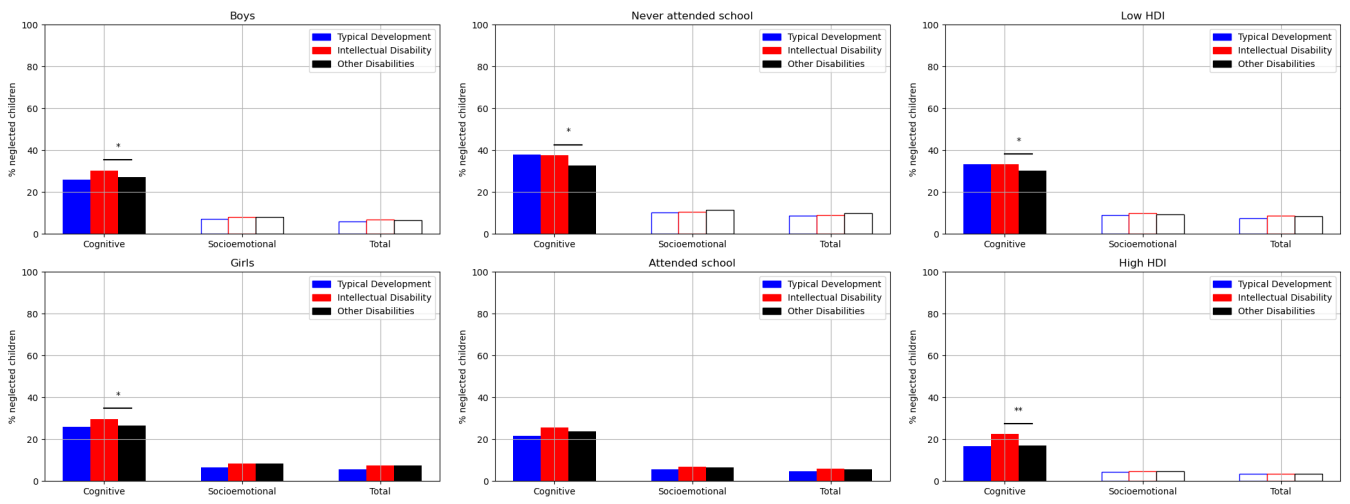

Figure 3: Percentages of neglected children for each category of caregiving activities by education of the main caregiver (left) and HDI group of the country (right). White colored bars indicate non significant differences between the three groups. 


\subsubsection{By gender of child}

For boys, the association between child disability and being neglected is significant only for cognitive caregiving activities $\left(\chi^{2}(2, \mathrm{~N}=14,973)=11.59\right.$, $p=0.003$, Cramer's V $=0.028)$; while all categories are significantly associated for girls (Cognitive: $\chi^{2}(2, \mathrm{~N}=14,552)=7.13, p=0.028$, Cramer's V $=0.022$; Socioemotional: $\chi^{2}(2, \mathrm{~N}=14,552)=13.18, p=0.001$, Cramer's V $=0.030$; Total: $\chi^{2}(2, \mathrm{~N}=14,552)=20.45, p<0.001$, Cramer's $\left.\mathrm{V}=0.037\right)$.

A significant difference between ID and OD was found only for cognitive caregiving activities for both Boys $\left(\chi^{2}(1, \mathrm{~N}=4,486)=4.20, p=0.040\right.$, Cramer's $\left.\mathrm{V}=0.031, O R_{I D / O D}=1.16\right)$ and Girls $\left(\chi^{2}(1, \mathrm{~N}=4,153)=4.35\right.$, $p=0.037$, Cramer's $\left.\mathrm{V}=0.032, O R_{I D / O D}=1.18\right)$, indicating an increased risk of being neglected for children with ID.

\subsubsection{By education of primary caregiver}

For non-educated caregivers, the association between child disability and being neglected is significant only for caregiving activities $\left(\chi^{2}(2, \mathrm{~N}=8,756)\right.$ $=18.39, p<0.001$, Cramer's $\mathrm{V}=0.046)$, while all categories are significantly associated for educated caregivers (Cognitive: $\chi^{2}(2, \mathrm{~N}=20,769)=21.20$, $p<0.001$, Cramer's $\mathrm{V}=0.032$; Socioemotional: $\chi^{2}(2, \mathrm{~N}=6,62)=11.621$, $p=0.037$, Cramer's V $=0.018$; Total: $\chi^{2}(2, \mathrm{~N}=20,769)=9.15, p=0.010$, Cramer's $\mathrm{V}=0.021)$.

A significant difference between ID and OD was found only for cognitive caregiving activities for non educated caregivers $\left(\chi^{2}(1, \mathrm{~N}=2,992)=6.56\right.$, $p=0.010$, Cramer's V $\left.=0.047, O R_{I D / O D}=1.24\right)$.

\subsubsection{By HDI group}

When considering the HDI group of the country, the association between child disability and being neglected is significant only for caregiving activities for both low HDI $\left(\chi^{2}(2, \mathrm{~N}=18,049)=13.31, p=0.001\right.$, Cramer's $\left.\mathrm{V}=0.027\right)$, and high HDI $\left(\chi^{2}(2, \mathrm{~N}=11,476)=15.47, p<0.001\right.$, Cramer's $\left.\mathrm{V}=0.037\right)$, countries.

For cognitive caregiving activities we also found a significant difference between ID and OD for both low $\left(\chi^{2}(1, \mathrm{~N}=6,279)=4.77, p=0.029\right.$, Cramer's $\left.\mathrm{V}=0.028, O R_{I D / O D}=1.14\right)$ and high $\left(\chi^{2}(1, \mathrm{~N}=2,360)=9.13\right.$, $p=0.003$, Cramer's $\left.\mathrm{V}=0.062, O R_{I D / O D}=1.41\right)$ HDI countries, indicating an increased risk of being neglected for children with ID. 
Table 6: Results of the multilevel logistic regression, with the coefficient and p-value of each term, for the three types of caregiving activities.

\begin{tabular}{lcccccc} 
& \multicolumn{2}{c}{ Cognitive } & \multicolumn{2}{c}{ Socioemotional } & \multicolumn{2}{c}{ Total } \\
& Coefficient & p-value & Coefficient & p-value & Coefficient & p-value \\
\hline Intellectual disability group & -0.0433 & 0.008818 & -0.0101 & 0.535191 & 0.00552 & 0.733685 \\
Parent & 0.52264 & $<0.000001$ & 0.67523 & $<0.000001$ & 0.65196 & $<0.000001$ \\
Gender of child & -0.0172 & 0.295517 & 0.02089 & 0.197527 & 0.01727 & 0.286291 \\
Education of caregiver & -0.1125 & $<0.000001$ & -0.0371 & 0.026967 & -0.0554 & 0.000903 \\
Human Development Index & -0.2519 & $<0.000001$ & -0.2802 & $<0.000001$ & -0.265 & $<0.000001$ \\
\hline
\end{tabular}

\subsection{Multilevel Logistic Regression}

The results of the multilevel logistic regression (Table 6 confirmed the Pearson $\chi^{2}$ results, showing that the difference between ID and OD is significant for the cognitive caregiving activities. The type of parent, education of the main caregiver and the HDI of the country are also significant in predicting whether the child is neglected.

\section{Discussion}

From the exploratory analysis of the incidence of general child disability and population characteristics (namely, child gender, level of education of parents, and country HDI), three main findings were uncovered. Firstly, there is significant difference in the incidence of child disability between male and female children, with males more likely to have ID and OD than females. This is in line with multiple studies that had previously revealed higher male prevalence in ID (Lai et al., 2012b), autism spectrum disorder (Lai et al., 2012a), and certain learning disabilities such as dyslexia (Chan et al., 2007).

Secondly, child disability is generally more prevalent among non-educated parents. Thirdly, child disability is also generally more prevalent in countries with lower HDI, corresponding to lower socioeconomic statuses (Programme, 2019; Deb, 2015). According to the standardized residuals reported in the above section, parental education and HDI demonstrate robust effects in the difference in prevalence of children with ID and OD, especially when compared to the prevalence of children with TD. The second and third findings may in fact be inter-related. These findings aligned with findings from other global studies across the world that reported greater prevalence of disability in low-income households (Boyle et al., 2011; Leonard et al., 2005; Magnus, 
2000; Drews et al., 1995). Coupled with the finding that there are higher barriers to entry in accessing education in LMICs (Lynch and O'riordan, 1998; King and Hill, 1993), it may be as (Emerson, 2012) posited: that LMICs present with greater instances of adverse conditions that are both detrimental to the prenatal and postpartum development of the child that result in delayed child development as well as to the opportunities given to parents to pursue education. Alternatively, another theory suggested by (Dubow et al., 2009) relating to education level, income and child development posits that parents who were not educated are less prepared to model behaviours that are adaptive for their child to develop optimally. Uneducated parents are more commonly residing in LMICs, due to the lack of opportunity and ability to secure higher-paying jobs elsewhere (Kenn, 2016). Both theories would support this pattern of findings in the present study; however, further research is required to clarify which theory is more relevant in explaining the direction of the relationships between education, HDI and child disability.

Moreover, it is noted that among the children who have been classified to have a disability using the Ten Questions tool, we are unable to distinguish between children who have only mild symptoms of disability, and therefore would not receive a formal diagnosis, and children who would qualify for a clinical diagnosis of disability.

According to (Zaman et al., 1990), of the children who did not receive a formal diagnosis despite testing positive in the Ten Questions (78\%), although $70 \%$ of these children had a form of mild disability or health condition, $30 \%$ had no disability. Therefore, the significant values from the OD and ID samples likely are contributed by an even smaller group of children. The uncovered effect sizes are likely to then be even stronger than is reported in this present study, if we exclude up to $30 \%$ of non-clinically positive cases.

\subsection{Caregiving and Developmental Disabilities}

Examining child disability with parental caregiving, it was revealed that children with developmental disabilities are generally more likely to be neglected by all caregivers (mothers, fathers and other caregivers), and that this neglect was more prominent in cognitive caregiving as compared to socioemotional caregiving. Specifically, among children with disabilities, children with ID are also more likely to be neglected in the area of cognitive caregiving as compared to OD, with a particularly large effect size as calculated by the standardized residuals reported in the previous section. This finding is sup- 
ported by different studies, making use of a range of methodologies, that consistently found child developmental disability to be a risk factor for neglect in caregiving (Leeb et al., 2012; Eshbaugh et al., 2011; Hibbard et al., 2007; Embry, 2001). The difference in level of neglect of children with developmental disabilities has been found to be three times that of a typical child (Sullivan and Knutson, 2000). (Stormont, 2001) posited that this may be due to the difficulty in sustaining a warm responsive parenting style towards children with developmental disabilities. As the maintenance of parents' caregiving behaviour correlates to their child's level of receptiveness (Wheeler et al., 2007), a lack of social feedback from the children would discourage caregivers from continuing with their caregiving activities. This is especially pertinent as developmental disabilities manifest behaviourally and physically with signs and symptoms that reduce the likelihood of active parent-child interaction (Warren and Brady, 2007). Examples of these symptoms may be low rates of social initiation that reduces the frequency of parent-child interaction, and avoidant gaze which decreases social engagement.

The significant difference in cognitive caregiving, especially between children with ID and OD, may be attributed to similar reasons. Drawing reference from the transactional model of development proposed by (Sameroff, 2009), both caregiver and child are involved in a dynamic, changing interaction where both parties play a role in shaping the developmental outcomes and the external environment which either reinforce or undermine the effects of the interaction. In the case of cognitive caregiving, the differences in the ability to interact and engage cognitively with a child with ID compared to a child with OD or TD become more salient due to the nature of ID. These differences may be exacerbated in the environmental context of LMICs where child-friendly resources such as picture books or educational toys are less common. Caregivers are then required to rely on their own effort and available resources to engage in cognitive caregiving with their child with little external support, which can quickly become discouraging to the caregivers. Conversely, neglectful caregiving can also lead to significantly delayed cognitive development (Strathearn et al., 2001). Together, these directions of interactions within the dynamics of parent, child and the environment may form a negative, even destructive, cycle of parent-child transactions. 


\subsubsection{Analysis by parent}

When examining caregiving practices by fathers, mothers and other caregivers separately, it emerged that children with disabilities tended to be more neglected by mothers. Specifically, in the area of cognitive caregiving, children with ID are significantly more neglected than children with OD. On the other hand, fathers showed significant correlation in cognitive caregiving neglect and type of disability, but there was no significant difference between ID and OD for any aspect of paternal caregiving. As explained above, the difference in level of neglect for cognitive caregiving among both mothers and fathers may be due to the nature of ID symptoms, which increases the difficulty of engaging the child cognitively.

\subsubsection{Analysis by gender of child}

Findings revealed that the gender of the child also played a significant role in the likelihood of caregiving neglect, especially for girls who were disabled, who were significantly more likely to be neglected for both cognitive and socioemotional caregiving, as well as overall caregiving measures. Between the ID and OD groups, however, both boys and girls with ID were more likely to be neglected along the cognitive domain than children with OD, which was discussed in the previous section. The higher likelihood of neglect among female children with disability seems in contrast with some findings reporting higher neglect among male children (Egry et al., 2015), and especially among male children with disability (Hua et al., 2014; Sobsey et al., 1997), as well as studies that found no significant difference in child gender on neglect (Cui et al., 2016). The present findings may present a different definition of neglect as compared to the above cited research, which contained multiple aspects of child neglect ranging from structural, medical, educational neglect to affective and psychological neglect (Sobsey et al., 1997), as well as deprivation of protection (Egry et al., 2015). As neglect in this study focused only on neglect in socioemotional and cognitive nurturance, our findings may have captured a difference in gender profile for different categories of child neglect. As explained by (Cui et al., 2016), the levels of neglect may be viewed in conjunction with gender-linked expectations of children. For example, male children are more likely to face higher expectations from parents in terms of abilities, educational attainment and eventual old-age support of the parents (Hannum et al., 2009), which may explain the higher level of caregiving af- 
forded to male children as compared to female children, who are consequently more likely to be neglected.

\subsubsection{Analysis by education level}

Analysing the results based on the education level of primary caregiver, it emerged that for educated caregivers, there is significant difference in the level of neglect towards children depending on disability status in both cognitive and socioemotional aspects of caregiving. Additionally, in cognitive caregiving, children with ID are more likely to be neglected than children with OD. These results might be explained by considering the relative burden of caring for a child with disability. According to (Green, 2007), there are two sources of burden when caring for child disability, namely objective and subjective burden. Objective burden refers to socio-structural constraints, such as the tangible or monetary resources that are required by the parents, or the availability of public health infrastructure to support child disability. Subjective burden refers to non-quantifiable emotional distress that caregivers face in the daily tasks of caregiving. As a higher level of educational attainment is typically correlated with higher-paying careers and therefore more financial resources (Gregorio and Lee, 2002), it can be reasoned that objective burden faced by more educated caregivers is relatively lower. However, the social stigma associated with child disability (Currie and Szabo, 2020; Ellen Selman et al., 2018; Thrush and Hyder, 2014) and social withdrawal or isolation as a result of such stigma (Ngo et al., 2012) is a significant source of subjective burden. As caregivers who are more educated have more social capital and thus more to lose (Green et al., 2012), the burden of social stigma and withdrawal may be greater compared to uneducated caregivers. Significantly, findings from (Ngo et al., 2012) point specifically to the elevated social exclusion, labelling, and need to hide the child's condition in the case of ID, which may explain the significant difference even in the level of neglect between children with ID and OD. Qualitative findings also suggested several reasons for this discrepancy being the prevailing norm that children with ID are unable to be employed (Ngo et al., 2012), which is a concern that perhaps is more salient to more educated caregivers who are able to command higher salaries from their employment. Overall, this may lead to a net increase in burden for more educated caregivers, which then translated into lower quality of caregiving and greater neglect in the present findings.

On the other hand, non-educated caregivers are significantly more likely 
to neglect cognitive compared to socioemotional aspects of caregiving when parenting a child with disability. Taking into account the same model of relative burden in caring (Green, 2007), we propose that the pattern of findings among non-educated caregivers are due to high objective burden. The nature of cognitive caregiving as characterised by MICS includes the use of educational resources such as storybooks and other objects around the house (to count, draw, and tell the time with), which increase the level of objective burden. Taken together with the fact that children with disabilities will require specialised tools and resources to do the same activities (such as simplified books for children with ID or larger typefont for children with visual impairment), less educated caregivers with a smaller amount of dispensable income (Gregorio and Lee, 2002) may face greater difficulty in accessing and providing resources for cognitive caregiving of children with disabilities.

\subsubsection{Analysis by HDI}

Finally, findings when analysing by HDI level showed that caregivers from both low and high HDI countries show greater neglect in cognitive caregiving towards children with disabilities in general. Children with ID are also more neglected than children with OD in this aspect. These findings may be less reflective of difference in terms of HDI status, but rather more reflective of generally greater neglect of children with disabilities and especially ID in terms of cognitive caregiving. This aligns with long-established findings that children with ID spend overall less time in activities that were cognitive in nature (Ehrmann et al., 1995; Margalit, 1984; Matthews, 1979). The neglect by caregivers in the area of cognitive caregiving may be due to a history of viewing child ID under the lens of a health problem, rather than an educational one, as it was perceived that children with ID cannot be educated or developed cognitively. The prevailing perception of child ID is powerful in parental beliefs of the efficacy of cognitive caregiving of said child, which translates to whether or not the caregivers choose to engage in cognitive caregiving for a child with ID (Mutua and Dimitrov, 2001; Danseco, 1997). This was the case for child ID in England in the 1970s, prior to introducing educational policies for children with ID (Mittler, 2002). The perception of child ID from a biomedical health model rather than a biopsychosocial model also entailed that caregivers and parents often were not working effectively with professional healthcare personnel to deliver whole-person care for the child (Rogers, 2011). 


\section{$5 \quad$ Limitations}

As with all studies, the present study has several limitations in the methodology. Due to the usage of MICS as the dataset analysed, the obtained data and criteria of child disability was not based on a clinical assessment of developmental disability. A clinical assessment and diagnosis of child disability has several benefits. Firstly, as outlined above, a clinical assessment may be better able to rule out false positives which would in turn strengthen the effect sizes reported in the present study. Secondly, clinical diagnoses would enable a standardization of child disability internationally, which is of critical importance in a cross-national study. Thirdly, a clinical diagnosis may be able to provide further insight into the specific type of disability and its severity, both of which are factors that moderate the caregivers' choice of caregiving strategy or lack thereof (Wei and Jennifer, 2012; Eddy and Engel, 2008; Jaudes and Shapiro, 1999). Additionally, as disability brings about social stigma and some households may face negative perception from others regarding their child's developmental status (Werner and Shulman, 2013) and their caregiving practices, there may be issues of social desirability (Bornstein et al., 2015) due to the self-report nature of MICS. Future studies may wish to consider other modes of data collection that can supplement self-reported questionnaire data. Lastly, the dataset obtained from MICS is based on a cross-sectional study, and only correlational analyses can be conducted. Therefore, this study is unable to ascertain causal relationships between the factors identified above.

\section{Implications}

Notwithstanding, the current study sheds light upon parenting practices depending on developmental status of the child in LMICs. The above findings have highlighted a significant gap in the caregiving practices for children with ID, and especially in the area of cognitive caregiving, in LMICs. The present study marks an important step towards understanding the current situation of child intellectual disability in countries that have typically been underrepresented in empirical studies, and attempts to apply existing models and theories of child ID and caregiving in a new context based on data-driven methods. It is seen that caregivers tend to neglect children with ID more so than children with OD or typical development, and may be attributable 
to the stigma of ID, as well as the lack of knowledge of how best to engage cognitively with children with ID.

Through this study, it is hoped that vulnerable children with ID can receive higher quality caregiving. In LMICs, lower levels of caregiving and higher neglect may be better explained by larger sociological constructs such as SES, education and healthcare infrastructure (Kotch et al., 1995), while the same pattern of caregiving and neglect in countries of high income may more likely be due to individual parenting factors such as parenting stress (Dubowitz and Bennett, 2007). In (Bywaters et al., 2016) and (Slack et al., 2004) work investigating SES and neglect, SES is better characterized by the level of economic hardship experienced, which was predictive of level of child neglect. Individual parenting characteristics were then found to moderate this relationship between economic hardship and neglect ()(Slack et al., 2004). In the context of LMICs where economic hardship is more salient, it may be prudent to empower parents in LMICs through comprehensive establishment of economic, educational and social safety nets to address the main relationship between poverty and child neglect, rather than targeted parenting interventions. The findings suggest that LMICs may also consider large-scale destigmatization campaigns and specialized caregiver education regarding child ID to be useful in filling in the gap of cognitive caregiving for children with ID. 


\section{Author contribution}

A.B. and G.E conceived the study, A.B. and G.S. processed and analyzed the data; G.G. curated the data and the public repository; A.B. and M.L. wrote the draft of the manuscript; all authors read and approved the final version of the manuscript.

\section{Conflicts of interest}

The authors declare no conflict of interest.

\section{Funding}

A.B. was supported by a Post-doctoral Fellowship within MIUR programme framework "Dipartimenti di Eccellenza" (DiPSCO, University of Trento). G.E. was supported by NAP SUG 2015, Singapore Ministry of Education ACR Tier 1 (RG149/16 and RT10/19).

Computational resources were provided by the National Super Computing Center of Singapore (Project ID: 12001609; Computational study of Child Development in Low Resource Contexts).

\section{References}

Anthony, L. G., Anthony, B. J., Glanville, D. N., Naiman, D. Q., Waanders, C., and Shaffer, S. (2005). The relationships between parenting stress, parenting behaviour and preschoolers' social competence and behaviour problems in the classroom. Infant and Child Development: An International Journal of Research and Practice, 14(2):133-154.

Baio, J. (2014). Prevalence of autism spectrum disorder among children aged 8 years-autism and developmental disabilities monitoring network, 11 sites, united states, 2010.

Behrman, J. R., Cheng, Y., and Todd, P. E. (2004). Evaluating preschool programs when length of exposure to the program varies: A nonparametric approach. Review of economics and statistics, 86(1):108-132. 
Belsky, J. (1984). The determinants of parenting: A process model. Child development, pages 83-96.

Bizzego, A., Lim, M., Schiavon, G., and Esposito, G. (2020). Children with developmental disabilities in low- and middle-income countries: More neglected and physically punished. International journal of environmental research and public health, 17(19):7009.

Bornstein, M. H. (1985). How infant and mother jointly contribute to developing cognitive competence in the child. Proceedings of the National Academy of Sciences, 82(21):7470-7473.

Bornstein, M. H. (2014). Handbook of cultural developmental science. Psychology Press.

Bornstein, M. H. and Hendricks, C. (2013). Screening for developmental disabilities in developing countries. Social science \&f medicine, 97:307-315.

Bornstein, M. H. and Putnick, D. L. (2012). Cognitive and socioemotional caregiving in developing countries. Child development, 83(1):46-61.

Bornstein, M. H., Putnick, D. L., Bradley, R. H., Deater-Deckard, K., and Lansford, J. E. (2016). Gender in low- and middle-income countries. Monographs of the Society for Research in Child Development, 81(1).

Bornstein, M. H., Putnick, D. L., Lansford, J. E., Pastorelli, C., Skinner, A. T., Sorbring, E., Tapanya, S., Uribe Tirado, L. M., Zelli, A., Alampay, L. P., et al. (2015). Mother and father socially desirable responding in nine countries: Two kinds of agreement and relations to parenting self-reports. International Journal of Psychology, 50(3):174-185.

Bornstein, M. H., Tal, J., Rahn, C., Galperin, C. Z., Pecheux, M.-G., Lamour, M., Toda, S., Azuma, H., Ogino, M., and Tamis-LeMonda, C. S. (1992). Functional analysis of the contents of maternal speech to infants of 5 and 13 months in four cultures: Argentina, france, japan, and the united states. Developmental Psychology, 28(4):593.

Boyle, C. A., Boulet, S., Schieve, L. A., Cohen, R. A., Blumberg, S. J., Yeargin-Allsopp, M., Visser, S., and Kogan, M. D. (2011). Trends in the prevalence of developmental disabilities in us children, 1997-2008. Pediatrics, 127(6):1034-1042. 
Brooks, J. B. (1981). The process of parenting.

Bywaters, P., Bunting, L., Davidson, G., Hanratty, J., Mason, W., McCartan, C., and Steils, N. (2016). The relationship between poverty, child abuse and neglect: an evidence review. York: Joseph Rowntree Foundation.

Chan, D. W., Ho, C. S.-h., Tsang, S.-m., Lee, S.-h., and Chung, K. K. (2007). Prevalence, gender ratio and gender differences in reading-related cognitive abilities among chinese children with dyslexia in hong kong. Educational Studies, 33(2):249-265.

Christianson, A., Zwane, M., Manga, P., Rosen, E., Venter, A., Downs, D., and Kromberg, J. (2002). Children with intellectual disability in rural south africa: prevalence and associated disability. Journal of Intellectual Disability Research, 46(2):179-186.

Cui, N., Xue, J., Connolly, C. A., and Liu, J. (2016). Does the gender of parent or child matter in child maltreatment in china? Child Abuse $\mathcal{E}$ Neglect, 54:1-9.

Currie, G. and Szabo, J. (2020). Social isolation and exclusion: the parents' experience of caring for children with rare neurodevelopmental disorders. International Journal of Qualitative Studies on Health and Wellbeing, 15(1):1725362.

Danseco, E. R. (1997). Parental beliefs on childhood disability: Insights on culture, child development and intervention. International Journal of Disability, Development and Education, 44(1):41-52.

De Wolff, M. S. and Van Ijzendoorn, M. H. (1997). Sensitivity and attachment: A meta-analysis on parental antecedents of infant attachment. Child development, 68(4):571-591.

Deb, S. (2015). Gap between gdp and hdi: Are the rich country experiences different from the poor. In IARIW-OECD Special Conference.

Department of Health and Social Care (2001). Valuing people: A new strategy for learning disability for the 21st century. 
DeTemple, J., Snow, C., van Kleeck, A., Stahl, S., and Bauer, E. (2003). On reading books to children: parents and teachers.

Drews, C. D., Yeargin-Allsopp, M., Decoufle, P., and Murphy, C. C. (1995). Variation in the influence of selected sociodemographic risk factors for mental retardation. American journal of public health, 85(3):329-334.

Dubow, E. F., Boxer, P., and Huesmann, L. R. (2009). Long-term effects of parents' education on children's educational and occupational success: Mediation by family interactions, child aggression, and teenage aspirations. Merrill-Palmer quarterly (Wayne State University. Press), 55(3):224.

Dubowitz, H. and Bennett, S. (2007). Physical abuse and neglect of children. The Lancet, 369(9576):1891-1899.

Durkin, M. S., Davidson, L. L., Desai, P., Hasan, Z. M., Khan, N., Shrout, P. E., Thorburn, M. J., Wang, W., and Zaman, S. S. (1994). Validity of the ten questions screen for childhood disability: results from populationbased studies in bangladesh, jamaica, and pakistan. Epidemiology, pages 283-289.

Durkin, M. S., Wang, W., Shrout, P. E., Zaman, S. S., Hasan, Z., Desai, P., and Davidson, L. (1995). Evaluating a ten questions screen for childhood disability: reliability and internal structure in different cultures. Journal of clinical epidemiology, 48(5):657-666.

Eddy, L. L. and Engel, J. M. (2008). The impact of child disability type on the family. Rehabilitation nursing, 33(3):98-103.

Egan, K. (2001). Getting it wrong from the beginning: The mismatch between school and children's minds.

Egry, E. Y., Apostólico, M. R., Albuquerque, L. M., Gessner, R., and Fonseca, R. M. G. S. d. (2015). Understanding child neglect in a gender context: a study performed in a brazilian city. Revista da Escola de Enfermagem da USP, 49(4):0556-0563.

Ehrmann, L. C., Aeschleman, S. R., and Svanum, S. (1995). Parental reports of community activity patterns: A comparison between young children with disabilities and their nondisabled peers. Research in developmental disabilities, 16(4):331-343. 
Eisenberg, N., Fabes, R. A., and Spinrad, T. (2006). Handbook of child psychology. John Wiley \& Sons.

Ellen Selman, L., Fox, F., Aabe, N., Turner, K., Rai, D., and Redwood, S. (2018). "you are labelled by your children's disability"-a communitybased, participatory study of stigma among somali parents of children with autism living in the united kingdom. Ethnicity 83 Health, 23(7):781-796.

Embry, R. (2001). Examination of risk factors for maltreatment of deaf children: Findings from a national survey. In 7 th International Family Violence Research Conference, Portsmouth, NH.

Emde, R. and Feinman, S. (1992). Social referencing and the social construction of reality in infancy.

Emerson, E. (2012). Deprivation, ethnicity and the prevalence of intellectual and developmental disabilities. J Epidemiol Community Health, 66(3):218224 .

Engle, P., Black, M., Behrman, J., de Mello, M., Gertler, P., Kapiriri, L., et al. (2007). Child development in developing countries 3. Strategies to avoid the loss of developmental potential in more than, 200.

Eshbaugh, E. M., Peterson, C. A., Wall, S., Carta, J. J., Luze, G., Swanson, M., and Jeon, H.-J. (2011). Low-income parents' warmth and parentchild activities for children with disabilities, suspected delays and biological risks. Infant and Child Development, 20(5):509-524.

Fatimilehin, I. A. and Nadirshaw, Z. (1994). A cross-cultural study of parental attitudes and beliefs about learning disability (mental handicap). Mental Handicap Research, 7(3):202-227.

for Disease Control, C. and Prevention (2019). Developmental disabilities. Accessed: 2020-05-15.

Gaad, E. (2004). Cross-cultural perspectives on the effect of cultural attitudes towards inclusion for children with intellectual disabilities. International Journal of Inclusive Education, 8(3):311-328.

Green, M. T., Duncan, P., Salter, C., and Chavez, E. (2012). The educated worker: An empirical investigation of expectations of leadership. Journal of Leadership, Accountability and Ethics, 9(6):94-112. 
Green, S. E. (2007). "we're tired, not sad": Benefits and burdens of mothering a child with a disability. Social Science \& Medicine, 64(1):150-163.

Gregorio, J. D. and Lee, J.-W. (2002). Education and income inequality: new evidence from cross-country data. Review of income and wealth, 48(3):395416.

Hannum, E., Kong, P., and Zhang, Y. (2009). Family sources of educational gender inequality in rural china: A critical assessment. International journal of educational development, 29(5):474-486.

Hassall, R., Rose, J., and McDonald, J. (2005). Parenting stress in mothers of children with an intellectual disability: The effects of parental cognitions in relation to child characteristics and family support. Journal of intellectual disability research, 49(6):405-418.

Hastings, R. P. (2002). Parental stress and behaviour problems of children with developmental disability. Journal of Intellectual \&5 Developmental Disability, 27(3):149-160.

Hendricks, C., Lansford, J. E., Deater-Deckard, K., and Bornstein, M. H. (2014). Associations between child disabilities and caregiver discipline and violence in low-and middle-income countries. Child development, 85(2):513-531.

Henrich, J., Heine, S. J., and Norenzayan, A. (2010). Most people are not weird. Nature, 466(7302):29-29.

Hibbard, R. A., Desch, L. W., on Child Abuse, C., Neglect, et al. (2007). Maltreatment of children with disabilities. Pediatrics, 119(5):1018-1025.

Hua, J., Mu, Z., Nwaru, B. I., Gu, G., Meng, W., and Wu, Z. (2014). Child neglect in one-child families from suzhou city of mainland china. $B M C$ international health and human rights, 14(1):8.

Jaudes, P. K. and Shapiro, L. D. (1999). Child abuse and developmental disabilities. Young children and foster care: A guide for professionals, pages $213-234$.

Kenn, G. (2016). Education, skills, and decent work in low and middle income countries: Trends and results from an adult skills survey. Education for people and planet: creating sustainable futures for all. 
King, E. M. and Hill, M. A. (1993). Women's education in developing countries: Barriers, benefits, and policies. The World Bank.

Kotch, J. B., Browne, D. C., Ringwalt, C. L., Stewart, P. W., Ruina, E., Holt, K., Lowman, B., and Jung, J.-W. (1995). Risk of child abuse or neglect in a cohort of low-income children. Child abuse \& neglect, 19(9):1115-1130.

Lai, D.-C., Tseng, Y.-C., Hou, Y.-M., and Guo, H.-R. (2012a). Gender and geographic differences in the prevalence of autism spectrum disorders in children: Analysis of data from the national disability registry of taiwan. Research in developmental disabilities, 33(3):909-915.

Lai, D.-C., Tseng, Y.-C., Hou, Y.-M., and Guo, H.-R. (2012b). Gender and geographic differences in the prevalence of intellectual disability in children: Analysis of data from the national disability registry of taiwan. Research in developmental disabilities, 33(6):2301-2307.

Leeb, R. T., Bitsko, R. H., Merrick, M. T., and Armour, B. S. (2012). Does childhood disability increase risk for child abuse and neglect? Journal of Mental Health Research in Intellectual Disabilities, 5(1):4-31.

Leonard, H., Petterson, B., De Klerk, N., Zubrick, S. R., Glasson, E., Sanders, R., and Bower, C. (2005). Association of sociodemographic characteristics of children with intellectual disability in western australia. Social science $\&$ medicine, 60(7):1499-1513.

Lynch, K. and O'riordan, C. (1998). Inequality in higher education: A study of class barriers. British Journal of Sociology of education, 19(4):445-478.

Magnus, P. (2000). Correlations between socioeconomic status, level of iq and aetiology in mental retardation: a populationbased study of norwegian children. Social Psychiatry and Psychiatric Epidemiology, 35:12-8.

Margalit, M. (1984). Leisure activities of learning disabled children as a reflection of their passive life style and prolonged dependency. Child psychiatry and human development, 15(2):133-141.

Matthews, P. R. (1979). The frequency with which the mentally retarded participate in recreation activities. Research Quarterly. American Alliance for Health, Physical Education, Recreation and Dance, 50(1):71-79. 
Maulik, P. K. and Darmstadt, G. L. (2007). Childhood disability in lowand middle-income countries: overview of screening, prevention, services, legislation, and epidemiology. Pediatrics, 120(Supplement 1):S1-S55.

Maulik, P. K., Mascarenhas, M. N., Mathers, C. D., Dua, T., and Saxena, S. (2011). Prevalence of intellectual disability: a meta-analysis of populationbased studies. Research in developmental disabilities, 32(2):419-436.

Mittler, P. (2002). Educating pupils with intellectual disabilities in england: Thirty years on. International Journal of Disability, Development and Education, 49(2):145-160.

Mung'ala-Odera, V., Meehan, R., Njuguna, P., Mturi, N., Alcock, K., Carter, J., and Newton, C. (2004). Validity and reliability of the 'ten questions' questionnaire for detecting moderate to severe neurological impairment in children aged 6-9 years in rural kenya. Neuroepidemiology, 23(1-2):67-72.

Mutua, K. and Dimitrov, D. M. (2001). Prediction of school enrolment of children with intellectual disabilities in kenya: the role of parents' expectations, beliefs, and education. International Journal of Disability, Development and Education, 48(2):179-191.

Ngo, H., Shin, J. Y., Nhan, N. V., and Yang, L. H. (2012). Stigma and restriction on the social life of families of children with intellectual disabilities in vietnam. Singapore medical journal, 53(7):451-457.

Noel, M., Peterson, C., and Jesso, B. (2008). The relationship of parenting stress and child temperament to language development among economically disadvantaged preschoolers. Journal of child language, 35(4):823-843.

Oelofsen, N. and Richardson, P. (2006). Sense of coherence and parenting stress in mothers and fathers of preschool children with developmental disability. Journal of Intellectual and developmental Disability, 31(1):112 .

Olusanya, B. O., Davis, A. C., Wertlieb, D., Boo, N.-Y., Nair, M., Halpern, R., Kuper, H., Breinbauer, C., De Vries, P. J., Gladstone, M., et al. (2018). Developmental disabilities among children younger than 5 years in 195 countries and territories, 1990-2016: a systematic analysis for the global burden of disease study 2016. The Lancet Global Health, 6(10):e1100e1121. 
Osborne, L. A. and Reed, P. (2009). The relationship between parenting stress and behavior problems of children with autistic spectrum disorders. Exceptional Children, 76(1):54-73.

Pan, K.-m. (2007). Children and the millennium development goals: Progress towards a world fit for children. Unicef.

Papousek, H. and Bornstein, M. H. (1992). Didactic interactions: Intuitive parental support of vocal and verbal development in human infants. Nonverbal vocal communication: Comparative and developmental approaches, pages 209-229.

Pelchat, D., Lefebvre, H., and Perreault, M. (2003). Differences and similarities between mothers' and fathers' experiences of parenting a child with a disability. Journal of child health care, 7(4):231-247.

Programme, U. N. D. (2019). Human development index. Accessed: 202005-27.

Rapley, M. (2004). The social construction of intellectual disability. Cambridge University Press.

Rogers, C. (2011). Mothering and intellectual disability: partnership rhetoric? British Journal of Sociology of Education, 32(4):563-581.

Rosen, K. S. and Rothbaum, F. (1993). Quality of parental caregiving and security of attachment. Developmental Psychology, 29(2):358.

Rothbaum, F. and Weisz, J. R. (1994). Parental caregiving and child externalizing behavior in nonclinical samples: A meta-analysis. Psychological bulletin, 116(1):55.

Ruddick, L. and Oliver, C. (2005). The development of a health status measure for self-report by people with intellectual disabilities. Journal of Applied Research in Intellectual Disabilities, 18(2):143-150.

Sameroff, A. (2009). The transactional model. American Psychological Association.

Schalock, R. L., Borthwick-Duffy, S. A., Bradley, V. J., Buntinx, W. H., Coulter, D. L., Craig, E. M., Gomez, S. C., Lachapelle, Y., Luckasson, R., 
Reeve, A., et al. (2010). Intellectual disability: Definition, classification, and systems of supports. ERIC.

Scior, K. (2011). Public awareness, attitudes and beliefs regarding intellectual disability: A systematic review. Research in developmental disabilities, 32(6):2164-2182.

Slack, K. S., Holl, J. L., McDaniel, M., Yoo, J., and Bolger, K. (2004). Understanding the risks of child neglect: An exploration of poverty and parenting characteristics. Child maltreatment, 9(4):395-408.

Sobsey, D., Randall, W., and Parrila, R. K. (1997). Gender differences in abused children with and without disabilities. Child Abuse 85 Neglect, 21(8):707-720.

Standley, J. and Whipple, J. (2003). Music therapy with pediatric patients: A meta-analysis. music therapy in pediatric healthcare. Am Music Ther Assoc, 18.

Stormont, M. (2001). Preschool family and child characteristics associated with stable behavior problems in children. Journal of Early Intervention, 24(4):241-251.

Strathearn, L., Gray, P. H., O'Callaghan, M. J., Wood, D. O., et al. (2001). Childhood neglect and cognitive development in extremely low birth weight infants: A prospective study. Pediatrics, 108(1):142-151.

Sullivan, P. M. and Knutson, J. F. (2000). Maltreatment and disabilities: A population-based epidemiological study. Child abuse 83 neglect, 24(10):1257-1273.

Tamis-Lemonda, C., Katz, J. C., and Bornstein, M. H. (2002). Infant play: Functions and partners. In Introduction to infant development, pages 229243. Oxford University Press.

Taraban, L. and Shaw, D. S. (2018). Parenting in context: Revisiting belsky's classic process of parenting model in early childhood. Developmental Review, 48:55-81.

Tassé, M. J. and Grover, M. (2013). American association on intellectual and developmental disabilities. Encyclopedia of autism spectrum disorders. Springer, New York, pages 122-125. 
Thiessen, E. D., Hill, E. A., and Saffran, J. R. (2005). Infant-directed speech facilitates word segmentation. Infancy, 7(1):53-71.

Thrush, A. and Hyder, A. (2014). The neglected burden of caregiving in lowand middle-income countries. Disability and health journal, 7(3):262-272.

Tomanik, S., Harris, G. E., and Hawkins, J. (2004). The relationship between behaviours exhibited by children with autism and maternal stress. Journal of Intellectual and Developmental Disability, 29(1):16-26.

UNICEF et al. (2008). Monitoring child disability in developing countries. New York.

United Nations Children's Fund (2006). Multiple indicator cluster survey manual 2005.

Warren, S. F. and Brady, N. C. (2007). The role of maternal responsivity in the development of children with intellectual disabilities. Mental retardation and developmental disabilities research reviews, 13(4):330-338.

Wei, X. and Jennifer, W. Y. (2012). The concurrent and longitudinal effects of child disability types and health on family experiences. Maternal and Child Health Journal, 16(1):100-108.

Werner, S. and Shulman, C. (2013). Subjective well-being among family caregivers of individuals with developmental disabilities: the role of affiliate stigma and psychosocial moderating variables. Research in developmental disabilities, 34(11):4103-4114.

Wheeler, A., Hatton, D., Reichardt, A., and Bailey, D. (2007). Correlates of maternal behaviours in mothers of children with fragile $\mathrm{x}$ syndrome. Journal of Intellectual Disability Research, 51(6):447-462.

Wong, S. Y., Wong, T. K., Martinson, I., Lai, A. C., Chen, W., and He, Y. (2004). Needs of chinese parents of children with developmental disability. Journal of Learning Disabilities, 8(2):141-158.

Zaman, S. S., Khan, N. Z., Islam, S., Banu, S., Dixit, S., Shrout, P., and Durkin, M. (1990). Validity of the 'ten questions' for screening serious childhood disability: results from urban bangladesh. International journal of epidemiology, 19(3):613-620. 